\title{
Study of the allelopathic activity of Garcinia pedunculata Roxb
}

\author{
Md. Mahfuzur Rob ${ }^{*}$ and Hisashi Kato-Noguchi
}

\author{
Laboratory of Plant Biochemistry, Department of Applied Biological Science, Faculty of Agriculture, Kagawa \\ University, Miki, Kagawa, 761-0795, Japan
}

\section{*Corresponding author: mahfuzrob@gmail.com}

\begin{abstract}
The allelopathic properties of plants can be used as an alternative weed control method to reduce the use of synthetic herbicides. Accordingly, the present study was carried out to determine the allelopathic activity of Garcinia pedunculata. Six different concentrations of aqueous methanol extracts of $G$. pedunculata fruit were prepared and used to determine their effect on the growth of eight test plants: alfalfa (Medicago sativa L.), cress (Lepidum sativum L.), lettuce (Lactuca sativa L.), rapeseed (Brassica napus L.), barnyard grass (Echinochloa crus-galli (L.) P. Beauv.), foxtail fescue (Vulpia myuros (L.) C.C. Gmel.), Italian ryegrass (Lolium multiflorum Lam.), and timothy (Phleum pratense L.). The test plants were grown in Petri dishes and after $48 \mathrm{~h}$ incubation, the length of the roots and shoots of the seedlings was measured and compared with control seedlings. Experiments were carried out in a completely randomized design (CRD). Analysis of variance (ANOVA) of the data was performed using the SPSS statistical package, and the $I_{50}$ values were measured from a regression equation. The extracts at each concentration significantly inhibited the shoot and root growth of all the test plants, except the concentration of $0.001 \mathrm{~g}$ dry weight equivalent extract $/ \mathrm{mL}$, compared with control. At a concentration of $0.3 \mathrm{~g}$ of dry weight equivalent extract $/ \mathrm{mL}$, the shoot and root growth of all the tested plants were completely inhibited, except the shoot growth of barnyard grass. The degree of inhibition increased in line with increased extract concentration. The shoots of alfalfa and the roots of barnyard grass were determined to be the most susceptible to the $G$. pedunculata extract based on the concentration of extract resulting in $50 \%\left(I_{50}\right)$ growth inhibition of the test plants. These results suggest that $G$. pedunculata may have allelopathic potential and may possess allelochemicals. From our study, we can conclude that $G$. pedunculata could be developed as an eco-friendly weed control option.
\end{abstract}

Keywords: Allelopathy; growth inhibition; aqueous methanol extract; weed control.

Abbreviations: $I_{50}$ concentration required for $50 \%$ inhibition; CRD_completely randomized design.

\section{Introduction}

Weeds compete with cultivated plants and severely affect the production of crops. Therefore, since ancient times, weeds have been treated as a serious threat to crop plants (Zimdahl et al., 2018). In fact, weeds alone account for the biggest yield loss among all the biotic and abiotic stresses (Nawaz et al., 2014). According to a previous report, more than one-third of yield losses is due to weed infestation of major crops grown all over the world (Jabran et al., 2015). As populations grow and available resources decrease, weed management is now more important and challenging, and precise weed management is mandatory for food safety. Synthetic herbicides are widely used to control weed infestations due to their easy availability, time efficiency, and high control efficiency (Grisi et al., 2015). However, excessive use of synthetic herbicides has adversely affected sustainable agriculture and the environment (Chauhan et al., 2018). Additionally, the high selection pressure of herbicides also increases herbicide-resistant weeds. At least 254 species of weeds worldwide have been reported to have herbicide resistance (Heap, 2018). Therefore, environmental and health issues have spurred scientists to develop alternative ways to control weeds. A diversity of protection tools can ensure sustainable weed control and lower the risk of synthetic herbicides (Tuyen et al., 2018). A naturally occurring phenomenon, allelopathy, can be used to combat weed stress in an eco-friendly manner. The ability of one plant to influence the growth, development, and reproduction of neighboring plants by releasing secondary metabolites (called allelochemicals) is called allelopathy (Zeng et al., 2014; Latif et al., 2017).

Garcinia is one of the largest genera of the Clusiaceae family of trees or shrubs found in tropical Asia, Africa, and Polynesia (CSIR, 1956). Garcinia pedunculata Roxb. is a large evergreen tree with a stout trunk and spreading branches. Its fruit is roundish, becomes deep yellow during ripening (Sarma and Devi, 2015), and is unappetizing because of its acid taste (Joseph et al., 2005). Although G. pedunculata is a wildgrowing species, it has been domesticated in some parts of India (Sarma and Devi, 2015). In Bangladesh, it is an underutilized fruit found in the north-eastern part of the country. The mature fruit is seldom used in cooking to impart sourness in curries and pulses (Islam et al., 2015), but it has many medicinal properties including antidiabetic, antiscorbutic, antidiarrhoeic, astringent, and cardiotonic (Vo et al., 2012; Sarma et al., 2016; Ali et al., 2017). To date, many 
studies have explored the pharmacological activity of $G$. pedunculata, but no attention has been paid to its allelopathic activity. Therefore, the aim of the present study was to investigate the allelopathic potential of Garcinia pedunculata fruit.

\section{Results}

\section{The effect of the aqueous methanol extracts of Garcinia} pedunculata on the shoot growth of the test plant species

The shoot growth of the eight test plant species was significantly influenced by the aqueous methanol extracts of $G$. pedunculata fruit (Figs. 1 and 2). An increasing concentration of $G$. pedunculata extract proportionately inhibited the shoot growth of the test plants. At a concentration of $0.01 \mathrm{~g}$ dry weight equivalent extract $/ \mathrm{mL}$, the shoot growth of cress, lettuce, rapeseed, barnyard grass, and foxtail fescue was less than $30 \%$ of control shoot growth, while alfalfa, timothy, and Italian rye grass were $34.5,55.1$, and $60.2 \%$ of control shoot growth, respectively. Similarly, at $0.03 \mathrm{~g}$ dry weight equivalent extract $/ \mathrm{mL}$, the shoot growth of all the test plants was inhibited by more than $80 \%$, except timothy. At $0.1 \mathrm{~g}$ dry weight equivalent extract $/ \mathrm{mL}$, the shoots of alfalfa, lettuce, rapeseed, and foxtail fescue were completely inhibited, whereas Italian ryegrass, cress, barnyard grass, and timothy were inhibited to $1.1,3.1,4.2$, and $5.2 \%$ of control, respectively (Fig. 2). With exposure to $0.3 \mathrm{~g}$ dry weight equivalent extract $/ \mathrm{mL}$, the shoot growth of all the test plants was completely inhibited, except barnyard grass. Furthermore, the extract reduced the overall mean shoot growth of alfalfa, cress, lettuce, rapeseed, barnyard grass, foxtail fescue, Italian rye grass, and timothy to $30.9,32.1,29.6,29.1,28.8,32.5$, 38.6 , and $43.4 \%$ of control, respectively (Fig. 4).

Correlation analysis between $G$. pedunculata extract concentration and shoot growth depicted a very strong negative correlation in all the test plants, and the Pearson correlation coefficient varied from -0.927 to $-0.962(p<0.01)$ (Table 1). The $I_{50}$ values for the shoot growth of the test plants ranged from 0.003 to $0.013 \mathrm{~g}$ dry weight equivalent extract $/ \mathrm{mL}$ (Table 2). A lower $I_{50}$ value indicates stronger extract activity against a test plant. Based on the $I_{50}$ values, alfalfa showed the highest sensitivity and timothy showed the lowest sensitivity to the extracts.

\section{The effect of the aqueous methanol extracts of Garcinia} pedunculata on the root growth of the test plant species

The effect of the aqueous methanol extracts of $G$. pedunculata on the root growth of the test plant species is presented in Fig. 1 and Fig. 3 . The extracts at all the concentrations suppressed the root length of the test plants. The root length of alfalfa, cress, lettuce, rapeseed, barnyard grass, foxtail fescue, Italian ryegrass, and timothy was inhibited to $36.5,33.3,29.7,13.8$, $6.1,20.7,18.6$, and $47.5 \%$ of control, respectively, by $0.01 \mathrm{~g}$ dry weight equivalent extract $/ \mathrm{mL}$. Compared with control, 0.1 $\mathrm{g}$ dry weight equivalent extract/mL completely inhibited the root growth of alfalfa, lettuce, rapeseed, and barnyard grass, while the root growth of cress, foxtail fescue, Italian ryegrass, and timothy was reduced to $2.6,0.6,0.5$, and $1.3 \%$ of control, respectively. The strongest inhibition was found with the concentration of $0.3 \mathrm{~g}$ dry weight equivalent extract $/ \mathrm{mL}$, for which the root growth of all the tested plants was completely inhibited. In addition, the extract inhibited the overall mean root growth of alfalfa, cress, lettuce, rapeseed, barnyard grass, foxtail fescue, Italian rye grass, and timothy to $33.3,32.0,28.5$, $23.2,15.1,27.3,29.8$, and $36.0 \%$ of control, respectively (Fig. 4).

The correlation coefficient between the extract of $G$. pedunculata and root length was very strong, and values ranged from -0.856 to -0.961 (Table 1 ). The $I_{50}$ values for the root growth of the test plants ranged between 0.001 and $0.009 \mathrm{~g}$ dry weight equivalent extract $/ \mathrm{mL}$ (Table 2). Based on the $I_{50}$ values, inhibition by the extract was highest for barnyard grass and lowest for timothy.

\section{Discussion}

The aqueous methanol extracts of $G$. pedunculata detrimentally influenced the growth of the dicotyledonous plants (alfalfa, cress, lettuce, and rapeseed) and monocotyledonous plants (barnyard grass, foxtail fescue, Italian ryegrass, and timothy). Such inhibition of the growth of the test plants by the extracts might be due to the allelopathic properties of G. pedunculata. The growth inhibitory activity of the $G$. pedunculata extracts varied with extract concentration: the higher the extract concentration the greater the inhibition of the test plants. This result suggests the potential of $G$. pedunculata to inhibit growth could be due to inhibitory substances. Concentration-dependent inhibitory activity was also reported by Mahmoud et al. (2016) and Kato-Noguchi et al. (2016). The inhibitory effect of the extracts on the test plants might be through a variety of mechanisms such as reduced mitotic activity in the growing parts of the plant, decreased ion absorption rate, inhibition of photosynthetic respiration, and malfunctioning of enzyme activity (Rice, 1984) The extracts of $G$. pedunculata showed different inhibitory activities on different test plants, indicating selectivity of the growth inhibitory substances against target species. Tuyen et al. (2018) found differential inhibition of target species by allelochemicals, and some plants are more sensitive than others. This type of growth inhibition was also documented by Tanveer et al. (2010), who showed that E. helioscopia extract inhibited the growth of Lens culinaris and Cicer arietinum to a much greater extent than Triticum aestivum. The differences in specificity of extracts on test plants under laboratory conditions may be due to the innate biochemical and physiological properties of each test plant (Kobayashi et al., 2004).

From the results, it appears the roots of the test plant species were more sensitive to the $G$. pedunculata extracts than the shoots, except the roots of alfalfa and cress (Fig. 4). Root sensitivity to phytotoxic substances is the best indicator of the allelopathic effect of plant extracts (Grisi et al., 2012; Ladhari et al., 2013). Several previous studies have also reported that the inhibitory effect of plant extracts is more pronounced on root growth than shoot growth (Liu et al., 2018; Sbai et al., 2016). Such root inhibition might be due to the higher permeability of root tissue, which allows more allelochemicals to enter the roots compared with shoots because the shoot surface is covered with a well-developed cuticular layer, whereas the root surface lacks this layer (Gulzar et al., 2016; Yoshimura et al., 2011). Another possible explanation is that root growth largely depends on cell proliferation, which is 
Table 1. Correlation between concentration of the extracts of G. pedunculata and shoot and root length of all the test plants.

\begin{tabular}{lll}
\hline \multirow{2}{*}{ Test plant species } & \multicolumn{2}{c}{ Correlation coefficient (R) } \\
\cline { 2 - 3 } Alfalfa & Shoot & Root \\
Cress & $-0.962^{* * *}$ & $-0.961^{* * *}$ \\
Lettuce & $-0.927^{* * *}$ & $-0.922^{* * *}$ \\
Rapeseed & $-0.942^{* * *}$ & $-0.959^{* * *}$ \\
Barnyard grass & $-0.955^{* * *}$ & $-0.856^{* * *}$ \\
Foxtail fescue & $-0.954^{* * *}$ & $-0.895^{* * *}$ \\
Italian ryegrass & $-0.943^{* * *}$ & $-0.939^{* * *}$ \\
Timothy & $-0.941^{* * *}$ & $-0.901^{* * *}$ \\
\hline - Indicates significance of correlation at p<0.001. & $-0.955^{* * *}$ & $-0.895^{* * *}$ \\
\hline
\end{tabular}

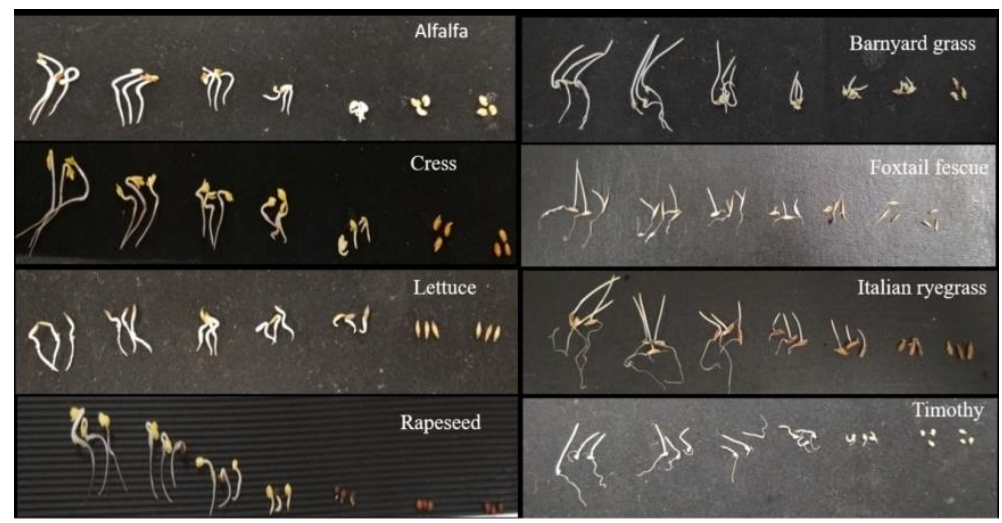

Fig 1. Effect of Garcinia pedunculata extracts on the growth of eight test plant species. Treatment concentrations (from left to right in each picture): Control, $0.001,0.003,0.01,0.03,0.1$, and $0.3 \mathrm{~g}$ dry weight equivalent extract of $\mathrm{G}$. pedunculata $/ \mathrm{mL}$.

Table 2. The concentration required for $50 \%$ inhibition $\left(I_{50}\right)$ of the shoot and root growth of the test plant species by the aqueous methanol extracts of Garcinia pedunculata.

\begin{tabular}{lcc}
\hline \multirow{2}{*}{ Test plant species } & \multicolumn{2}{c}{$I_{50}$ (g dry weight equivalent extract $/ \mathrm{mL}$ ) } \\
\cline { 2 - 3 } & Shoot & Root \\
\hline Alfalfa & 0.003 & 0.005 \\
Cress & 0.005 & 0.006 \\
Lettuce & 0.004 & 0.004 \\
Rapeseed & 0.004 & 0.003 \\
Barnyard grass & 0.004 & 0.001 \\
Foxtail fescue & 0.005 & 0.004 \\
Italian ryegrass & 0.013 & 0.005 \\
Timothy & 0.013 & 0.009 \\
\hline
\end{tabular}

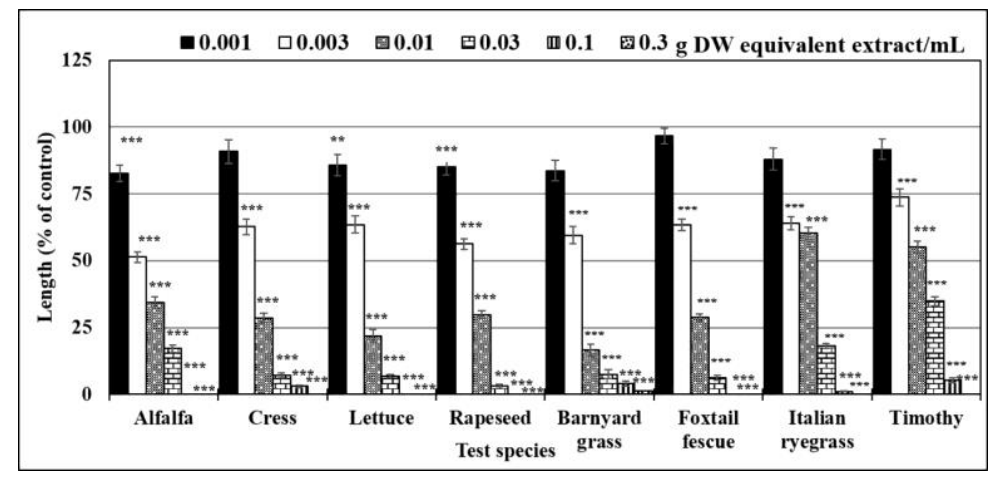

Fig 2. Effect of G. pedunculata extracts on the shoot growth of alfalfa, cress, lettuce, rapeseed, barnyard grass, foxtail fescue, Italian ryegrass, and timothy. All the test plant species were treated at the concentrations of $0.001,0.003,0.01,0.03,0.1$, and $0.3 \mathrm{~g}$ dry weight equivalent extract of $G$. pedunculata $/ \mathrm{mL}$. Mean \pm SE from two independent experiments with three replications for each treatment (number of seedlings per treatment=10, $n=60$ ). Each vertical bar represents standard error of the mean. Asterisks indicate significant differences between treatment and control: $* * p<0.01$ and ${ }^{* * *} p<0.001$. 


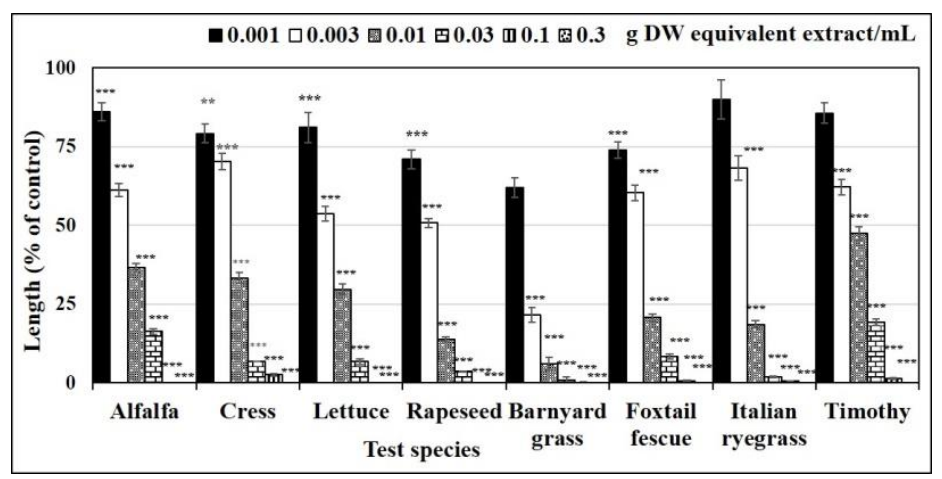

Fig 3. Effect of $G$. pedunculata extracts on the root growth of alfalfa, cress, lettuce, rapeseed, barnyard grass, foxtail fescue, Italian ryegrass, and timothy. All the test plant species were treated at the concentrations of $0.001,0.003,0.01,0.03,0.1$, and $0.3 \mathrm{~g}$ dry weight equivalent extract of $G$. pedunculata $/ \mathrm{mL}$. Mean \pm SE from two independent experiments with three replications for each treatment (number of seedlings per treatment $=10, n=60$ ). Each vertical bar represents standard error of the mean. Asterisks indicate significant differences between treatment and control: ${ }^{* *} p<0.01$ and ${ }^{* * *} p<0.001$.



Fig 4. Effect of $G$. pedunculata extract on overall mean growth of the shoots and roots of all the test plant species. Mean \pm SE from two independent experiments with three replications for each treatment $(n=60)$. Each vertical bar represents standard error of the mean. Asterisks indicate significant differences between shoot and root growth rates: ${ }^{* * *} p<0.001$, paired $t$-test.

drastically affected by phytotoxins, leading to restricted root growth (Tanveer et al., 2012; Yoshimura et al., 2011).

\section{Materials and Methods}

\section{Plant genotypes and sampling}

Garcinia pedunculata Roxb. fruits were collected from Jaintiapur Upazila $\left(25.1338^{\circ} \mathrm{N}\right.$ and $\left.92.1217^{\circ} \mathrm{E}\right)$, Sylhet, Bangladesh in August 2017. The collected fruit were individually washed under tap water to remove debris and tiny particles attached to the fruit. The fruit were then dried in the shade, ground into fine powder, and then stored at $2^{\circ} \mathrm{C}$ in a refrigerator until use.

\section{Test plant species}

Four dicotyledonous plants [alfalfa (Medicago sativa $\mathrm{L}$ ), cress (Lepidium sativum L.), lettuce (Lactuca sativa L.), rapeseed (Brassica napus L.)] and four monocotyledonous plants [barnyard grass (Echinochloa crus-galli (L.) P. Beauv.), foxtail fescue (Vulpia myuros (L.) C.C. Gmel.), Italian ryegrass (Lolium multiflorum Lam.), timothy (Phleum pratense L.)] were selected as test species. Alfalfa, cress, lettuce, rapeseed, and timothy were selected because of their known vegetative growth behavior while barnyard grass, Italian ryegrass, and foxtail fescue were selected for their worldwide distribution, mainly in crop fields.

\section{Extraction of G. pedunculata fruit}

The G. pedunculata fruit (100 g) powder was extracted with $400 \mathrm{~mL}$ of $70 \%$ aqueous methanol for $48 \mathrm{~h}$. The extract was then filtered through a sheet of filter paper (No. 2, $125 \mathrm{~mm}$, Advantec ${ }^{\circledR}$; Toyo Roshi Kaisha, Ltd., Tokyo, Japan) by using a vacuum pump. The residue, produced in the first extraction, was re-extracted with the same amount of cold methanol for $24 \mathrm{~h}$. The filtrates from the two extracts were mixed together and evaporated at $40^{\circ} \mathrm{C}$ until completely dry.

\section{Growth bioassay}

Crude extracts of $G$. pedunculata were dissolved in $250 \mathrm{~mL}$ methanol to prepare six assay concentrations $(0.001,0.003$, $0.01,0.03,0.1$, and $0.3 \mathrm{~g}$ dry weight equivalent extract $/ \mathrm{mL}$ ). To prepare those concentrates, an aliquot of the extracts was independently added to a sheet of filter paper (No. 2) in 28 $\mathrm{mm}$ Petri dishes. The methanol was then allowed to evaporate in a draft chamber, and $0.6 \mathrm{~mL}$ of $0.05 \%(\mathrm{v} / \mathrm{v})$ aqueous Tween 20 (polyoxyethylene sorbitan monolaurate; Nacalai, Kyoto, Japan) solution was added to each Petri dish. Then, 10 seeds 
of alfalfa, cress, lettuce, and rapeseed and 10 germinated seeds of barnyard grass, foxtail fescue, Italian ryegrass, and timothy (allowed to germinate for 90, 48, 48, and $60 \mathrm{~h}$, respectively; incubated in the dark at $25^{\circ} \mathrm{C}$ ) were set on the filter paper in the Petri dishes. The seeds in the Petri dishes treated with Tween 20 without extract were used as a control. The root and shoot lengths were measured after $48 \mathrm{~h}$ incubation in darkness at $25^{\circ} \mathrm{C}$. The seedling length percentage was recorded by referring to the control seedling lengths.

\section{Statistical analysis}

All experiments were carried out in a completely randomized design (CRD). Treatments and controls were duplicated and replicated three times (10 seeds/replication, $n=60)$. All experimental data were analyzed using SPSS version 22.0 (IBM Corp., 2016). Analysis of variance (ANOVA) of all the variables of each test plant was conducted, and significant differences were calculated using post-hoc Tukey's test at $p=0.05$. Significant differences between overall mean growth percentage of the shoots and roots were analyzed using a paired $t$-test at $p \leq 0.05$. The $I_{50}$ values of each test species were calculated from a regression equation of the concentration response curves. Two-tailed Pearson Correlation was used to check the correlation between extract concentration and the growth of the test plants.

\section{Conclusion}

The findings of this study showed that the Garcinia pedunculata extracts have the potential to inhibit the shoot and root growth of all the tested plants. Increasing extract concentration leading to increased inhibitory activity against the test plants suggests the allelopathic potential of Garcinia pedunculata and that it might contain growth inhibitory substances. Therefore, Garcinia pedunculata is a promising resource that could be used to isolate and characterize allelochemicals to develop bio-rational herbicides.

\section{Acknowledgements}

We thank MEXT (Monbukagakusho, Japan) for providing a scholarship to Md. Mahfuzur Rob. We also thank Professor Dennis Murphy for editing the English of the manuscript.

\section{References}

Ali M, Paul S, Tanvir EM, Hossen M, Rumpa NEN, Saha M, Gan SH (2017) Antihyperglycemic, antidiabetic, and antioxidant effects of Garcinia pedunculata in rats. J Evid Based Complementary Altern Med. 17: 1-15.

Chauhan A, Ranjan A, Jindal T (2018) Biological control agents for sustainable agriculture, safe water and soil health. In: Jindal T (ed) Paradigms in pollution prevention. Springer, Cham.

CSIR (1956) The wealth of India (raw materials), New Delhi, India. pp. 99-108.

Grisi PU, Forim MR, Costa ES, Anese S, Franco MF, Eberlin MN, Gualtieri SCJ (2015) Phytotoxicity and identification of secondary metabolites of Sapindus saponaria L. leaf extract. J Plant Growth Regul. 34: 339-349.

Grisi PU, Ranal MA, Gualtieri SCJ, Santana DG (2012) Allelopathic potential of Sapindus saponaria $\mathrm{L}$. leaves in the control of weeds. Acta Sci Agron. 34: 1-9.

Gulzar A, Siddiqui MB, Bi S (2016) Phenolic acid allelochemicals induced morphological, ultrastructural, and cytological modification on Cassia sophera L. and Allium cepa L. Protoplasma. 253: 1211-1221.

Heap I (2018) The international survey of herbicide resistant weeds. Available at www.weedscience.org. (Accessed June 11, 2018)

Islam MZ, Hoque MM, Asif-UI-Alam SM, Monalisa K (2015) Chemical composition, antioxidant capacities and storage stability of Citrus macroptera and Garcinia pedunculata fruits. Emir J Food Agric. 27: 275-282.

Jabran K, Mahajan G, Sardana V, Chauhan BS (2015) Allelopathy for weed control in agricultural systems. Crop Prot. 72: 57-65.

Joseph GS, Jayaprakasha GK, Selvi AT, Jena BS, Sakariah KK (2005) Antiaflatoxigenic and antioxidant activities of Garcinia extracts. Int J Food Microbiol. 101: 153-160.

Kato-Noguchi H, Suzuki M, Noguchi K, Ohno O, Suenaga K, Laosinwattana C (2016) A potent phytotoxic substance in Aglaia odorata Lour. Chem Biodivers. 13: 549-554.

Kobayashi K (2004) Factors affecting phytotoxic activity of allelochemicals in soil. Weed Biol Manag. 4: 1-7.

Ladhari A, Omezzine F, DellaGreca M, Zarrelli A, Haouala SZR (2013) Phytotoxic activity of Cleome arabica L. and its principal discovered active compounds. South Afr J Bot. 88: 341-351.

Latif S, Chiapusio G, Weston LA (2017) Allelopathy and the role of allelochemicals in plant defense. Adv Bot Res. 82: 19-54.

Liu J, Xie M, Li X, Jin H, Yang X, Yan Z, Qin B (2018) Main allelochemicals from the rhizosphere soil of Saussurea lappa (Decne.) Sch. Bip. and their effects on plants' antioxidase systems. Molecules. 23: 2506.

Mahmoud A, Singh SD, Muralikrishna KS (2016) Allelopathy in jatropha plantation: effects on seed germination, growth and yield of wheat in north-west India. Agric Ecosyst Environt. 231: 240-245.

Nawaz A, Farooq M, Cheema SA, Cheema ZA (2014) Role of allelopathy in weed management. In: Chauhan BS, Mahajan $G$ (eds) Recent advances in weed management. Springer, New York.

Rice EL (1984) Allelopathy, 2nd ed. Academic Press, New York, NY, p. 320

Sarma R, Devi R (2015) Ethnopharmacological survey of Garcinia pedunculata Roxb. fruit in six different districts of Assam, India. Int J Pharm Sci Invent. 4: 20-28.

Sarma R, Kumari S, Elancheran R, Deori M, Devi R (2016) Polyphenol rich extract of Garcinia pedunculata fruit attenuates the hyperlipidemia induced by high fat diet. Front Pharmacol. 7: 294.

Sbai H, Saad I, Ghezal N, Della Greca M, Haouala R (2016) Bioactive compounds isolated from Petroselinum crispum $\mathrm{L}$. leaves using bio guided fractionation. Ind Crop Prod. 89: 207-214.

Tanveer A, Jabbar MK, Kahliq A, Matloob A, Abbas RN, Javaid MM (2012) Allelopathic effects of aqueous and organic fractions of Euphorbia dracunculoides Lam. on germination and seedling growth of chickpea and wheat. Chil J Agric Res. 72: 495-501.

Tanveer A, Rehman A, Javaid MM, Abbas RN, Sibtain M, Ahmad AUH, Aziz A (2010) Allelopathic potential of Euphorbia helioscopia L. against wheat (Triticum aestivum L.), 
chickpea (Cicer arietinum L.) and lentil (Lens culinaris Medic.). Turk J Agric For. 34: 75-81.

Tuyen PT, Xuan TD, Tu Anh TT, Mai Van T, Ahmad A, Elzaawely AA, Khanh TD (2018) Weed suppressing potential and isolation of potent plant growth inhibitors from Castanea crenata Sieb. et Zucc. Molecules. 23: 345.

Vo HT, Nguyen NTT, Maas G, Werz UR, Pham HD, Nguyen LHD (2012) Xanthones from the bark of Garcinia pedunculata. Phytochem Lett. 5: 766-769.
Yoshimura H, Sawai Y, Tamotsu S, Sakai A (2011) 1, 8-cineole inhibits both proliferation and elongation of BY-2 cultured tobacco cells. J Chem Ecol. 37: 320-328.

Zeng RS (2014) Allelopathy-the solution is indirect. J Chem Ecol. 40: 515-516.

Zimdahl RL (2018) Fundamentals of weed science. 5th ed. Academic press, San Diego, USA, pp. 758. 